\title{
Age differences in interhemispheric interactions: callosal structure, physiological function, and behavior
}

\section{Brett W. Fling ${ }^{1,2}$, Scott J. Peltier ${ }^{3}$, Jin Bo ${ }^{1}$, Robert C. Welsh ${ }^{4,5}$ and Rachael D. Seidler ${ }^{1,2,6,7 *}$}

1 School of Kinesiology, University of Michigan, Ann Arbor, MI, USA

2 Institute of Gerontology, University of Michigan, Ann Arbor, MI, USA

${ }^{3}$ Department of Biomedical Engineering, University of Michigan, Ann Arbor, MI, USA

${ }^{4}$ Department of Radiology, University of Michigan, Ann Arbor, MI, USA

${ }^{5}$ Department of Psychiatry, University of Michigan, Ann Arbor, MI, USA

${ }^{6}$ Department of Psychology, University of Michigan, Ann Arbor, MI, USA

7 Neuroscience Program, University of Michigan, Ann Arbor, MI, USA

There is a fundamental gap in understanding how brain structural and functional network connectivity are interrelated, how they change with age, and how such changes contribute to older adults' sensorimotor deficits. Recent neuroimaging approaches including resting state functional connectivity MRI (fcMRI) and diffusion tensor imaging (DTI) have been used to assess brain functional ( $f C M R l)$ and structural (DTI) network connectivity, allowing for more integrative assessments of distributed neural systems than in the past. Declines in corpus callosum size and microstructure with advancing age have been well documented, but their contributions to age deficits in unimanual and bimanual function are not well defined. Our recent work implicates age-related declines in callosal size and integrity as a key contributor to unimanual and bimanual control deficits. Moreover, our data provide evidence for a fundamental shift in the balance of excitatory and inhibitory interhemispheric processes that occurs with age, resulting in age differences in the relationship between functional and structural network connectivity. Training studies suggest that the balance of interhemispheric interactions can be shifted with experience, making this a viable target for future interventions.

Keywords: interhemispheric, inhibition, aging, motor control

The brain is organized with certain specialized functions lateralized to each hemisphere. For example, the left hemisphere is preferentially involved in verbal processing (Ivry and Robertson, 1998) and motor control (Serrien et al., 2006), while the right hemisphere plays a stronger role in spatial cognition (Ivry and Robertson, 1998). Interhemispheric transfer via the corpus callosum plays a key role in the production of coherently integrated behavior, assuring a complex balance of excitatory and inhibitory processes. For specific motor behaviors, interhemispheric inhibition is required to prevent interference of control processes between the two hemispheres. Consider tying your shoes - each hand moves independently to accomplish a unified goal. While each primary motor cortex has dense projections to the muscles of the contralateral hand, the two are also highly interconnected via the corpus callosum, allowing for interhemispheric transfer of information (Figure 1). It is known that individuals with callosal damage or those who 


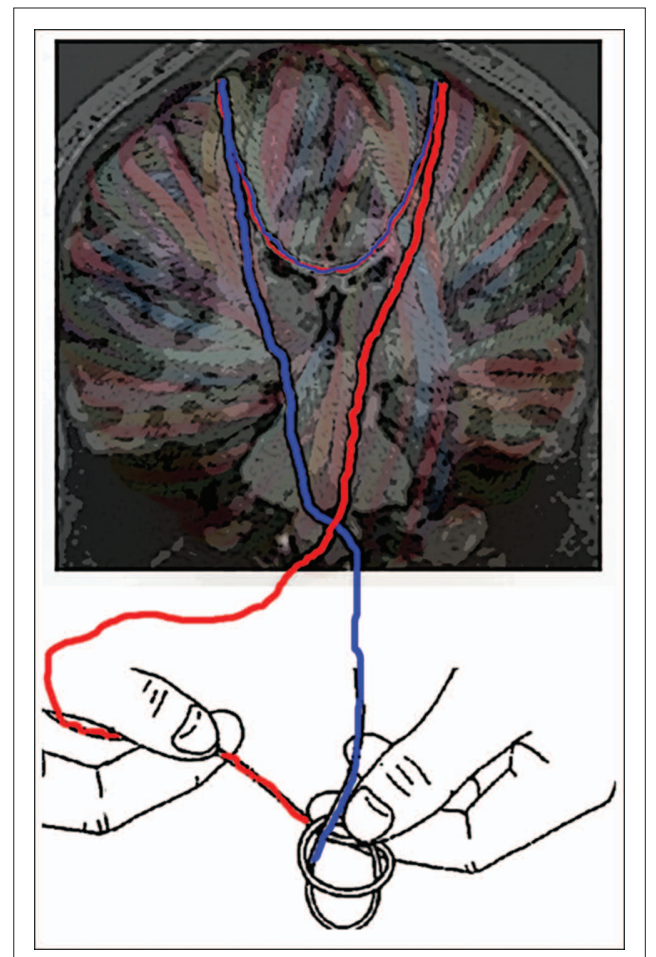

FIGURE 1 |The brain's white matter is conceptualized as yarn in this diagram. The descending strands represent corticospinal control of each hand by its respective contralateral motor cortex. The callosal strands represent the capacity for interhemispheric interactions. In an asynchronous bimanual task such as shoe tying, interhemispheric inhibition is relied upon to prevent interference between control processes for the two hands. At the same time, interhemispheric facilitation may be relied upon to integrate actions of the two hands, allowing them to achieve a single unified goal.

have undergone callosal section to alleviate severe epilepsy have particular difficulty with coordinating the two hands when each follows its own independent spatio-temporal path (Mark and Sperry, 1968; Kennerley et al., 2002), likely due to reduced interhemispheric inhibition. Indeed it has been shown using transcranial magnetic stimulation (TMS) that interhemispheric inhibition levels increase during bimanual tasks when the two hands move out of phase with each other (Giovannelli et al., 2009). This is thought to help alleviate interference that arises due to "motor overflow," or interhemispheric excitation resulting in too much sharing of information between the two motor cortices.

Here, we review the literature addressing the behavioral relevance of interhemispheric interactions between the sensorimotor cortices, including consideration of the changes that occur with advanced age. We advance the hypothesis that there is a fundamental shift with age in the relationships between callosal structure, callosal neurophysiological function, and motor performance. Numerous studies have identified age differences in brain structure, function, and biochemistry that are associated with deficits in motor and cognitive performance (for review see Seidler et al., 2010). For example, the corpus callosum undergoes significant degeneration with age both in terms of white matter quantity and quality (Fling et al., 2010; Sullivan et al., 2010). Additionally, work from our lab has documented age deficits in both unimanual (Seidler et al., 2002; Langan et al., 2010) and bimanual (Bangert et al., 2010; Fling et al., 2010) control. Recent research approaches using techniques to measure brain structural and functional network connectivity have begun to elucidate the detailed mechanisms by which corpus callosum pathways contribute to unimanual and bimanual motor behavior, as well as the functional consequences of age-related degeneration of interhemispheric connections. Investigating brain functional and structural network integrity has the potential to make a significant impact on the field of neuromotor control because it allows for assessment of distributed brain networks as opposed to focusing on individual brain structures. Indeed, the use of these techniques allows for evaluation of Geschwind's theory that white matter disruptions can be as detrimental to function as gray matter damage (Geschwind, 1965a,b).

\section{AGE DIFFERENCES IN BRAIN ACTIVATION PATTERNS}

The hemispheric asymmetry reduction in older adults (HAROLD) model, describing the finding that older adults (65+ years of age) demonstrate increased bilateral prefrontal cortex recruitment across different memory and cognitive tasks, was originally proposed by Cabeza (2001) a decade ago. In the interim, the effects of age on brain activation patterns and their relation to cognitive function have been studied extensively (cf. Li et al., 2001; Raz et al., 2007; Park and Reuter-Lorenz, 2009). Initial reports have suggested that over-recruitment patterns in older adults are reflective of either (i) compensatory activation where additional brain recruitment is positively associated with task performance (Cabeza, 2002; Reuter-Lorenz and Lustig, 2005; Heuninckx et al., 2008) or (ii) dedifferentiation suggesting that brain structure-function relationships become less distinctive with age and thus the increased brain activity has either no or negative behavioral consequences (Logan et al., 2002; Park et al., 2004; Langan et al., 2010). A 
recent model from Reuter-Lorenz and Cappell (2008), the compensation-related utilization of neural circuits hypothesis (CRUNCH) predicts that the distinctiveness of neural representations should be increased in older adults (relative to young adults) at low levels of task demand but reduced at high levels of demand. Consistent with the CRUNCH model, recent work from Carp et al. (2010) demonstrates both dedifferentiation- and compensation-like brain activation patterns in the same participants for the same task, arguing that comprehensive theories of cognitive aging must incorporate both interpretations of over-activation to fully explain complex patterns of age-related neuro-cognitive change.

While the literature on age-related differences in the neural control of movement has not developed as quickly, numerous studies have begun to elucidate the neural underpinnings associated with healthy aging and motor control (cf. Seidler et al., 2010). As proposed in the HAROLD model, older adults exhibit cortical over-activation relative to young adults when performing motor tasks. More symmetrical activation of the motor system (i.e., bilateral engagement of the motor cortices) in older adults is predominantly associated with increased engagement of the motor cortex ipsilateral to the moving hand (Calautti et al., 2001; Mattay et al., 2002; Ward and Frackowiak, 2003; Heuninckx et al., 2005, 2008; Langan et al., 2010). In our recent work, we reported that increased ipsilateral motor cortex activity was associated with poorer unimanual motor performance in older adults (Langan et al., 2010) indicating that the cognitive and motor systems may demonstrate distinct patterns of age-related change. Additional recent studies have provided insight into the role of interhemispheric interactions in the production of bilateral motor cortical activation in older adults.

\section{AGE DIFFERENCES IN RESTING STATE INTERHEMISPHERIC FUNCTIONAL CONNECTIVITY}

Resting state functional connectivity (fcMRI) studies have shown that remote but functionally related gray matter regions with known anatomical connections exhibit strong correlations in the low frequency $(<0.1 \mathrm{~Hz})$ blood oxygen level dependent (BOLD) signal when individuals are at rest (Biswal et al., 1995; Fox and Raichle, 2007; Rogers et al., 2007; Vincent et al., 2007). These correlations are highly spatially structured following anatomical networks and are therefore thought to reflect functional connectivity of the human brain. It is important to note, however, that fcMRI can provide insight beyond that of known anatomical connections. For example, a recent case study in an individual with a complete section of the corpus callosum revealed a striking loss of interhemispheric BOLD correlations, with the possible exception of the somatomotor system, hippocampal formation, and the thalamus (Johnston et al., 2008). Likewise Uddin et al. (2008) reported normal functional connectivity between interhemispheric middle occipital and cingulate gyri in an individual with complete commissurotomy. Because functional correlations can arise from multisynaptic pathways, fcMRI networks are not necessarily restricted to occur between structures with direct anatomical connections.

Three networks of relevance for motor control have been identified with fcMRI: (i) motor cortical, including interhemispheric primary motor, premotor, parietal, and supplementary motor cortex connectivity (Biswal et al., 1995; Peltier et al., 2005; Langan et al., 2010); (ii) striatal thalamo-cortical (Di Martino et al., 2008; Kelly et al., 2009; Kwak et al., 2010); and (iii) cerebellar thalamo-cortical (Krienen and Buckner, 2009). Along with others, we have made significant inroads into identifying the spatial structure and functional relevance of these networks in healthy young adults (Peltier et al., 2005; Biswal et al., 2010), older adults (Langan et al., 2010), and disease-affected individuals (Jelsone-Swain et al., 2010; Kwak et al., 2010).

Resting state functional network correlations have behavioral relevance. For example, default mode network connectivity is altered following visual (Lewis et al., 2009) or motor (Albert et al., 2009) learning. Additionally, medication-related changes in the frequency content of resting state striatal seed regions correlates with cognitive function in patients with Parkinson's disease (Kwak et al., 2010). Moreover, greater resting state motor interhemispheric connectivity in older adults is correlated with recruitment of the ipsilateral motor cortex during a unimanual task (motor overflow, Langan et al., 2010). In other words, while most patient groups exhibit disrupted (reduced) functional network connectivity, our recent data provide compelling evidence that older adults demonstrate increased connectivity of interhemispheric motor cortical networks compared to young adults (Langan et al., 2010). We propose that this reflects a release from the normally predominantly inhibitory interhemispheric projections, shifting the overall balance of interhemispheric interactions toward excitatory processes. 


\section{AGE DIFFERENCES IN CORPUS CALLOSUM MACRO- AND MICROSTRUCTURE}

Age differences in brain activation patterns are often posited to be the result of changes in brain structure. Transcallosal fibers connect largely homologous cortical regions of the right and left hemispheres; thus, the corpus callosum mediates the transfer and integration of lateralized cognitive, motor, and sensory information between cortices (Aboitiz, 1992). Structural magnetic resonance imaging (MRI) has demonstrated that there is substantial interindividual variability in callosal size and morphology for both young and older adults (Stancak et al., 2003; Fling et al., 2010; Raz et al., 2010; Sullivan et al., 2010). Interestingly, less lateralized task processing during both cognitive (Muller-Oehring et al., 2007) and motor (Langan et al., 2010) tasks has been shown to be associated with reductions in callosal cross-sectional area in older adults. Therefore, structural differences of the corpus callosum appear to impact cortical activity both at rest and during task performance, with significant implications for behavior.

An emerging body of literature indicates that not only is the quantity of white matter reduced in older adults, but the quality of remaining white matter is compromised as well (reviewed in Seidler et al., 2010). The use of conventional MRI allows for measurements of regional brain volume, while diffusion tensor imaging (DTI) allows assessment of white matter microstructure. Thus, DTI may be more sensitive to subtler agerelated white matter changes than conventional volumetric MRI. For example, some MRI investigations suggest that the corpus callosum does not undergo extensive volumetric declines with age (Raz et al., 2001), whereas several studies have shown declining callosal microstructure with age (Fling et al., 2010; Sullivan et al., 2010). Numerous studies have identified associations between callosal macrostructure or microstructure and behavior (Stancak et al., 2003; Fling et al., 2010; Sullivan et al., 2010). Furthermore, recent studies utilizing fiber tractography have demonstrated relationships between interhemispheric motor fiber tract microstructure and task performance in both healthy participants (Johansen-Berg et al., 2007) and in those with white matter dysfunction (Bartels et al., 2008; Bonzano et al., 2008; Kern et al., 2010). While individual differences in callosal quantity and quality have shown to be behaviorally relevant in both young and older adults, it appears there may be a fundamental shift with age in these relationships.

Interhemispheric communication can have either net facilitatory or inhibitory effects on the cortex (Chen et al., 2003). Multiple lines of research indicate that interhemispheric connections between the sensorimotor cortical regions have primarily inhibitory effects (Netz, 1999; De Gennaro et al., 2004; Lenzi et al., 2007). This interhemispheric inhibition is presumably to prevent interference from the opposite hemisphere, or motor overflow (cf. Hoy et al., 2004). This is thought to allow for simultaneous but independent control of the two hands, such as required for shoe tying. Intriguingly, we have recently reported that young adults with increased microstructural quality of callosal regions connecting sensorimotor cortical areas perform with more variability on unimanual and asynchronous bimanual motor tasks (Fling et al., 2010). Conversely, larger size and better microstructure of these same callosal regions was associated with better performance in older adults. Moreover, we recently reported that older adults exhibit greater recruitment of ipsilateral primary motor cortex during unimanual motor task performance, which was associated with longer reaction times (Langan et al., 2010). Additionally, greater recruitment of ipsilateral primary motor cortex in older adults was correlated with reduced resting state interhemispheric connectivity and a larger corpus callosum. We posit that reduced interhemispheric motor connectivity may be associated with a loss of the ability to inhibit the ipsilateral hemisphere during unimanual motor task performance for older adults, which has a negative impact on response time. These data provide evidence for a link between callosal structural and physiological changes with age, lending credence to the dedifferentiation hypothesis. Specifically, interhemispheric interactions require a balance between excitatory and inhibitory processes; taken together the aforementioned studies suggest that this overall balance is likely shifted in the aging brain.

\section{EVIDENCE FOR AGE DIFFERENCES IN INTERHEMISPHERIC NEUROPHYSIOLOGICAL FUNCTION}

Experiments conducted with individuals with callosal pathology (e.g., partial callosotomy or multiple sclerosis) demonstrate that while the total number of callosal fibers connecting the two primary motor cortices is relatively few in number, communication between these homologous areas has the capability to strongly influence motor behavior (Eliassen et al., 1999, 2000; Kennerley et al., 2002; Lenzi et al., 2007; Bonzano et al., 2008). The fiber tracts that comprise the corpus callosum are integral for 
inhibiting the ipsilateral motor cortex during both unimanual and bimanual control (Netz, 1999; Perez and Cohen, 2008; Vercauteren et al., 2008). Monosynaptic connections between primary motor cortices (Porter and Lemon, 1993), along with densely transcallosally connected secondary motor areas, have been shown to significantly influence interhemispheric inhibition and neuromotor control. Although full characterization of the transcallosal inhibitory sensorimotor network is still lacking, neuroimaging data suggest that it includes the supplementary and pre-supplementary motor areas (Serrien et al., 2002; Grefkes et al., 2008), the dorsal premotor cortices (Giovannelli et al., 2006; van den Berg et al., 2010), and the somatosensory cortices (Ni et al., 2009).

Callosally mediated interhemispheric inhibition is a complex process that has traditionally been measured in humans using paired-pulse TMS to each primary motor cortex at an interstimulus interval of (i) 8-12 ms (short-interval interhemispheric inhibition, SIHI) or (ii) $\sim 40 \mathrm{~ms}$ (long-interval interhemispheric inhibition, LIHI; cf. Chen, 2004). Paired-pulse TMS utilizes two magnetic stimulators to investigate the effect of a supra-threshold conditioning stimulus over one primary motor cortex (M1) on the size of a test motor evoked potential elicited by stimulation of the opposite M1. Although both SIHI and LIHI are reflective of transcallosal inhibition, they do not appear to represent the same phenomenon, nor are the two values correlated with each other across individuals (Chen et al., 2003). Although both measures reflect inhibition of synchronized activation of the corticospinal system induced by the conditioning stimulus (the first stimulus applied), a pharmacological experiment suggests that LIHI is likely mediated by postsynaptic gamma-aminobutyric acid type $\mathrm{B}(\mathrm{GABA})_{\mathrm{B}}$ receptors, whereas SIHI is potentially mediated by $\mathrm{GABA}_{\mathrm{A}}$ receptors, although this remains to be fully elucidated (Irlbacher et al., 2007).

In line with our hypothesis of reductions in interhemispheric inhibitory interactions with age, accumulating evidence demonstrates reduced inhibition within the nervous system of older adults, both at the cortical (Talelli et al., 2008a,b) and spinal levels (Kido et al., 2004). A discussion of age-related changes in inhibition at the spinal level is beyond the scope of the current review, and thus we will focus on cortical inhibition. Paired-pulse TMS studies have shown that healthy older adults display decreased excitability of intracortical inhibitory circuits within the motor cortex while at rest (Peinemann et al.,
2001). Task-related increases in LIHI also diminish with advancing age and are correlated with the degree of ipsilateral primary motor cortex recruitment during unimanual motor tasks (Talelli et al., 2008a,b). In agreement with Talelli and colleagues, Fujiyama et al. (2009) found that older adults have a reduced ability to modulate inhibitory function in a task-dependent manner in comparison to young adults. Specifically, older adults exhibited a reduced ability to increase inhibition during coordination of the arm and leg on the same side of the body. These agerelated declines in interhemispheric inhibition and in the ability to modulate inhibitory function to meet task demands may be associated with the bimanual movement deficits observed in older adults.

Considering that the unimanual and bimanual motor tasks included in Fling et al. (2010) and Langan et al. (2010) rely heavily on timing, some insight may be provided from research in expert musicians, individuals with exquisite temporal control. Surprisingly, both interand intra-hemispheric inhibition are reduced in musicians (Ridding et al., 2000; Nordstrom and Butler, 2002). It is interesting that cortical inhibition is less effective in musicians, who have extraordinary control of independent finger movements. However, it is unclear whether these effects represent an adaptive change related to exceptional control of finger movements or a maladaptive change brought about by overuse of the hand from extensive training (Nordstrom and Butler, 2002).

Training experiments may shed some light on the counterintuitive finding that musicians with superior bimanual control and larger callosal size have reduced interhemispheric inhibition. Shim et al. (2005) were the first to investigate the effects of practice on callosal physiology; following just 2 days of practice of a novel bimanual force production task, participants demonstrated task-selective reductions in interhemispheric inhibition. In accord with this finding, Hortobagyi et al. (2010) reported a significant decrease in interhemispheric inhibition and a concomitant increase in ipsilateral primary motor cortex excitability following 20 sessions of unimanual submaximal force production. These studies, taken together with those in trained musicians, suggest that interhemispheric inhibitory projections can show plastic changes that favor the execution of a practiced task, likely through a cooperative action of the two hemispheres (Shim et al., 2005). In other words, although interhemispheric inhibition is integral for the performance of coordinated bimanual tasks, it 


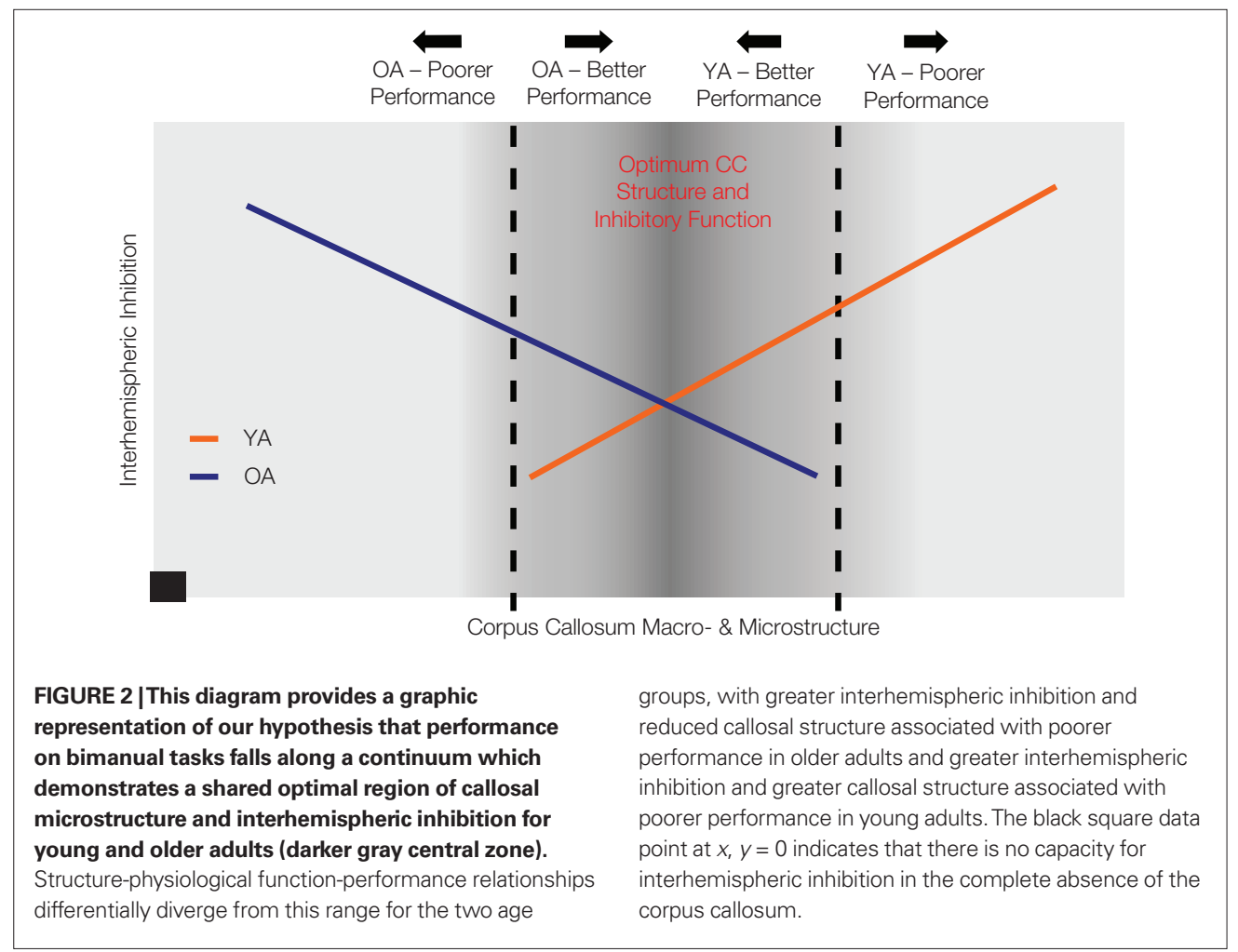

does not appear that high levels of inhibition are beneficial to task performance.

\section{SYNTHESIS AND FUTURE DIRECTIONS}

If decreased interhemispheric inhibition favors the performance of bimanual tasks, how can we reconcile decreased interhemispheric inhibition in older adults and decreased bimanual task performance? Recent work suggests that the microstructure of transcallosal motor fibers, assessed with DTI, reflects the capacity for interhemispheric inhibition between the primary motor cortices. Wahl et al. (2007) report a positive relationship between microstructural integrity of transcallosal motor fibers and strength of SIHI in young adults. No data is currently available regarding the nature of this relationship in older adults. Based upon our recent findings (Fling et al., 2010; Langan et al., 2010) it seems likely that there is a fundamental shift in the relationship between callosal size, microstructure, and interhemispheric physiologic function from young to older adults. Figure 2 presents a graphic representation of our hypothesis. This figure portrays the relationship between these neural measures of the callosum and performance of motor tasks requiring interhemispheric interactions for older and younger adults (see Figure 2). Based upon our recent findings (Fling et al., 2010; Langan et al., 2010), we suggest that in young adults, increased interhemispheric inhibitory function is associated with larger callosal size and increased fiber tract microstructure, whereas the inverse relationship is true in older adults. Furthermore, a parsimonious and testable hypothesis that builds upon our recent findings is that performance on bimanual tasks falls along a continuum which demonstrates a shared optimal region of callosal microstructure and interhemispheric inhibition for young and older adults. That is, young and older adults exhibit maximal performance for a comparable range of callosal microstructure and interhemispheric inhibition values. However, structure-physiological function-performance relationships differentially diverge from this range for the two age groups.

\section{ACKNOWLEDGMENTS}

This work was supported by National Institutes of Health [grant numbers AG024106 (Rachael D. Seidler), T32-AG000114], and the UM National Institutes of Health Claude D. Pepper Center Human Subjects and Assessment Core (grant number AG024824). Rachael D. Seidler is a member of the LIFE program (The LIFE Course: Evolutionary and Ontogenetic Dynamics). 


\section{REFERENCES}

Aboitiz, F. (1992). Brain connections: interhemispheric fiber systems and anatomical brain asymmetries in humans. Biol. Res. 25, 51-61.

Albert, N. B., Robertson, E. M., and Miall, R. C. (2009). The resting human brain and motor learning. Curr. Biol. 19, 1023-1027.

Bangert, A.S., Reuter-Lorenz, P.A., Walsh, C. M., Schachter, A. B., and Seidler, R. D. (2010). Bimanual coordination and aging: neurobehavioral implications. Neuropsychologia 48, 1165-1170.

Bartels, C., Mertens, N., Hofer, S., Merboldt, K. D., Dietrich, J., Frahm, J., and Ehrenreich, H. (2008). Callosal dysfunction in amyotrophic lateral sclerosis correlates with diffusion tensor imaging of the central motor system. Neuromuscul. Disord. 18, 398-407.

Biswal, B., Yetkin, F. Z., Haughton, V. M., and Hyde, J.S. (1995). Functional connectivity in the motor cortex of resting human brain using echo-planar MRI. Magn. Reson. Med. 34, 537-541.

Biswal, B. B., Mennes, M., Zuo, X. N., Gohel, S., Kelly, C., Smith, S. M., Beckmann, C. F., Adelstein, J. S., Buckner, R. L., Colcombe, S., Dogonowski, A. M., Ernst, M., Fair, D., Hampson, M., Hoptman, M. J., Hyde, J. S., Kiviniemi, V. J., Kotter, R., Li, S. J., Lin, C. P., Lowe, M. J., Mackay, C., Madden, D. J., Madsen, K. H., Margulies, D. S., Mayberg, H. S., McMahon, K., Monk, C. S., Mostofsky, S. H., Nagel, B. J., Pekar, J. J., Peltier, S. J., Petersen, S. E., Riedi, V., Rombouts, S. A., Rypma, B., Schlaggar, B. L., Schmidt, S., Seidler, R. D., Siegle, G. J., Sorg, C., Teng, G. J., Veijola, J., Villringer, A., Walter, M., Wang, L., Weng, X. C., Whitfield-Gabrieli, S., Williamson, P., Windischberger, C., Zang, Y. F., Zhang, H. Y., Castellanos, F. X., and Milham, M. P. (2010). Toward discovery science of human brain function. Proc. Natl. Acad. Sci. U.S.A. 107, 4734-4739.

Bonzano, L., Tacchino, A., Roccatagliata, L., Abbruzzese, G., Mancardi, G. L., and Bove, M. (2008). Callosal contributions to simultaneous bimanual finger movements. J. Neurosci. 28, 3227-3233.

Cabeza, R. (2001). Cognitive neuroscience of aging: contributions of functional neuroimaging. Scand. J. Psychol. 42, 277-286.

Cabeza, R. (2002). Hemispheric asymmetry reduction in older adults: the HAROLD model. Psychol. Aging 17, 85-100.

Calautti, C., Serrati, C., and Baron, J. C. (2001). Effects of age on brain activation during auditory-cued thumb-to- index opposition: a positron emission tomography study. Stroke 32, 139-146.

Carp, J., Gmeindl, L., and Reuter-Lorenz, P.A. (2010). Age differences in the neural representation of working memory revealed by multi-voxel pattern analysis. Front. Hum. Neurosci. 4:217. doi: 10.3389/fnhum.2010.00217

Chen, R. (2004). Interactions between inhibitory and excitatory circuits in the human motor cortex. Exp. Brain Res. 154, 1-10.

Chen, R., Yung, D., and Li, J. Y. (2003). Organization of ipsilateral excitatory and inhibitory pathways in the human motor cortex. J. Neurophysiol. 89, 1256-1264.

De Gennaro, L., Bertini, M., Pauri, F. Cristiani, R., Curcio, G., Ferrara, M., and Rossini, P. M. (2004). Callosal effects of transcranial magnetic stimulation (TMS): the influence of gender and stimulus parameters. Neurosci. Res. 48, 129-137.

Di Martino, A., Scheres, A., Margulies, D. S., Kelly, A. M., Uddin, L. Q., Shehzad, Z., Biswal, B., Walters, J. R., Castellanos, F. X., and Milham, M. P. (2008). Functional connectivity of human striatum: a resting state FMRI study. Cereb. Cortex 18, 2735-2747.

Eliassen, J. C., Baynes, K., and Gazzaniga, M. S. (1999). Direction information coordinated via the posterior third of the corpus callosum during bimanual movements. Exp. Brain Res. 128, 573-577.

Eliassen, J. C., Baynes, K., and Gazzaniga, M. S. (2000). Anterior and posterior callosal contributions to simultaneous bimanual movements of the hands and fingers. Brain 123(Pt 12), 2501-2511.

Fling, B. W., Walsh, C. M., Bangert, A. S. Reuter-Lorenz, P. A., Welsh, R. C., and Seidler, R. D. (2010). Differential callosal contributions to bimanual control in young and older adults. J. Cogn. Neurosci. doi: 10.1162/jocn.2010.21600. [Epub ahead of print].

Fox, M. D., and Raichle, M. E. (2007). Spontaneous fluctuations in brain activity observed with functional magnetic resonance imaging. Nat. Rev. Neurosci. 8, 700-711.

Fujiyama, H., Garry, M. I., Levin, O., Swinnen, S. P., and Summers, J. J. (2009). Age-related differences in inhibitory processes during interlimb coordination. Brain Res. 1262, 38-47.

Geschwind, N. (1965a). Disconnexion syndromes in animals and man. I. Brain 88, 237-294.

Geschwind, N. (1965b). Disconnexion syndromes in animals and man. II. Brain 88, 585-644.

Giovannelli, F., Borgheresi,A., Balestrieri, F., Ragazzoni,A.,Zaccara, G., Cincotta,
M., and Ziemann, U. (2006). Role of the right dorsal premotor cortex in "physiological" mirror EMG activity. Exp. Brain Res. 175, 633-640.

Giovannelli, F., Borgheresi, A., Balestrieri, F., Zaccara, G., Viggiano, M. P. Cincotta, M., and Ziemann, U. (2009). Modulation of interhemispheric inhibition by volitional motor activity: an ipsilateral silent period study. $J$. Physiol. 587(Pt 22), 5393-5410.

Grefkes, C., Eickhoff, S. B., Nowak, D. A., Dafotakis, M., and Fink, G. R. (2008). Dynamic intra- and interhemispheric interactions during unilateral and bilateral hand movements assessed with fMRI and DCM. Neuroimage 41, 1382-1394.

Heuninckx, S., Wenderoth, N., Debaere, F, Peeters, R., and Swinnen, S. P. (2005). Neural basis of aging: the penetration of cognition into action control. J. Neurosci. 25, 6787-6796.

Heuninckx, S., Wenderoth, N., and Swinnen, S. P. (2008). Systems neuroplasticity in the aging brain: recruiting additional neural resources for successful motor performance in elderly persons. J. Neurosci. 28, 91-99.

Hortobagyi, T., Richardson, S.P., Lomarev, M., Shamim, E., Meunier, S., Russman, H., Dang, N., and Hallett, M. (2010). Interhemispheric plasticity in humans. Med. Sci. Sports Exerc. doi: 10.1249/ MSS.0b013e31820a94b8. [Epub ahead of print].

Hoy, K. E., Fitzgerald, P. B., Bradshaw, J. L., Armatas, C. A., and GeorgiouKaristianis, N. (2004). Investigating the cortical origins of motor overflow. Brain Res. Brain Res. Rev. 46, 315-327.

Irlbacher, K., Brocke, J., Mechow, J. V. and Brandt, S. A. (2007). Effects of $\operatorname{GABA}(\mathrm{A})$ and $\mathrm{GABA}(\mathrm{B})$ agonists on interhemispheric inhibition in man. Clin. Neurophysiol. 118, 308-316.

Ivry, R. B., and Robertson, L. C. (1998). The Two Sides of Perception. Cambridge, MA: The Massachusetts Institute of Technology.

Jelsone-Swain, L. M., Fling, B. W., Seidler, R. D., Hovatter, R., Gruis, K., and Welsh, R. C. (2010). Reduced interhemispheric functional connectivity in the motor cortex during rest in limb-onset amyotrophic lateral sclerosis. Front. Syst. Neurosci. 4:158. doi: 10.3389/fnsys.2010.00158

Johansen-Berg, H., Della-Maggiore, V. Behrens, T. E., Smith, S. M., and Paus, T. (2007). Integrity of white matter in the corpus callosum correlates with bimanual co-ordination skills. Neuroimage 36(Suppl. 2), T16-T21.

Johnston, J. M., Vaishnavi, S. N., Smyth, M. D., Zhang, D., He, B. J., Zempel, J. M., Shimony, J. S., Snyder, A. Z., and Raichle, M. E. (2008). Loss of inter- hemispheric functional connectivity after complete section of the corpus callosum. J. Neurosci. 25, 6453-6458.

Kelly, C., de Zubicaray, G., Di Martino, A., Coplands, D. A., Reiss, P. T., Klein, D. F., Castellanos, F. X., Milham, M. P., and McMahon, K. (2009). L-dopa modulates functional connectivity in striatal cognitive and motor networks: a double-blind placebo-controlled study. J. Neurosci. 29, 7364-7678.

Kennerley, S. W., Diedrichsen, J., Hazeltine, E., Semjen, A., and Ivry, R. B. (2002). Callosotomy patients exhibit temporal uncoupling during continuous bimanual movements. Nat. Neurosci. 5, 376-381.

Kern, K. C., Sarcona, J., Montag, M. Giesser, B. S., and Sicotte, N. L. (2010). Corpus callosal diffusivity predicts motor impairment in relapsingremitting multiple sclerosis: a TBSS tractography study. Neuroimage 55 , 1169-1177

Kido, A., Tanaka, N., and Stein, R. B. (2004).Spinal excitation and inhibition decrease as humans age. Can. J. Physiol. Pharmacol. 82, 238-248.

Krienen, F. M., and Buckner, R. L. (2009). Segregated fronto-cerebellar circuits revealed by intrinsic functional connectivity. Cereb. Cortex 19, 2485-2497.

Kwak, Y., Peltier, S., Bohnen, N. I., Muller, M. L., Dayalu, P., and Seidler, R. D. (2010). Altered resting state corticostriatal connectivity in mild to moderate stage Parkinson's disease. Front. Syst. Neurosci. 4:143. doi: 10.3389/ fnsys.2010.00143

Langan, J., Peltier, S. J., Bo, J., Fling, B. W., Welsh, R. C., and Seidler, R. D. (2010). Functional implications of age differences in motor system connectivity. Front. Syst. Neurosci. 4:17 doi: 10.3389/fnsys.2010.00017

Lenzi, D., Conte, A., Mainero, C., Frasca, V., Fubelli, F., Totaro, P., Caramia, F., Inghilleri, M., Pozzilli, C., and Pantano, P. (2007). Effect of corpus callosum damage on ipsilateral motor activation in patients with multiple sclerosis: a functional and anatomical study. Hum. Brain Mapp. 28, 636-644.

Lewis, C. M., Baldassarre, A., Committeri, G., Romani, G. L., and Corbetta, M (2009). Learning sculpts the spontaneous activity of the resting human brain. Proc. Natl. Acad. Sci. U.S.A. 106, 17558-17563.

Li, S. C., Lindenberger, U., and Sikstrom, S. (2001). Aging cognition: from neuromodulation to representation. Trends Cogn. Sci. 5, 479-486.

Logan, J. M., Sanders, A. L., Snyder, A. Z., Morris, J.C., and Buckner, R. L. (2002). Under-recruitment and nonselective recruitment: dissociable neural mech- 
anisms associated with aging. Neuron 33, 827-840.

Mark, R. F., and Sperry, R. W. (1968). Bimanual coordination in monkeys. Exp. Neurol. 21, 92-104.

Mattay, V. S., Fera, F., Tessitore, A., Hariri, A. R., Das, S., Callicott, J. H., and Weinberger, D. R. (2002). Neurophysiological correlates of agerelated changes in human motor function. Neurology 58, 630-635.

Muller-Oehring, E. M., Schulte, T., Raassi, C., Pfefferbaum, A., and Sullivan, E. V. (2007). Local-global interference is modulated by age, sex and anterior corpus callosum size. Brain Res. 1142, 189-205.

Netz, J. (1999). Asymmetry in transcallosal inhibition. Electroencephalogr. Clin. Neurophysiol. Suppl.51, 137-144.

Ni, Z., Gunraj, C., Nelson, A. J., Yeh, I. J., Castillo, G., Hoque, T., and Chen, R. (2009). Two phases of interhemispheric inhibition between motor related cortical areas and the primary motor cortex in human. Cereb. Cortex 19, 1654-1665.

Nordstrom, M.A., and Butler, S. L. (2002). Reduced intracortical inhibition and facilitation of corticospinal neurons in musicians. Exp. Brain Res. 144, 336-342.

Park, D. C., Polk, T. A., Park, R., Minear, M., Savage,A., and Smith, M. R. (2004). Aging reduces neural specialization in ventral visual cortex. Proc. Natl. Acad. Sci. U.S.A. 101, 13091-13095.

Park, D. C., and Reuter-Lorenz, P. (2009). The adaptive brain: aging and neurocognitive scaffolding. Annu. Rev. Psychol. 60, 173-196.

Peinemann, A., Lehner, C., Conrad, B., and Siebner, H. R. (2001). Age-related decrease in paired-pulse intracortical inhibition in the human primary motor cortex. Neurosci. Lett. 313, 33-36.

Peltier, S. J., LaConte, S. M., Niyazov, D. M., Liu, J.Z., Sahgal, V., Yue, G. H., and Hu, X. P. (2005). Reductions in interhemispheric motor cortex functional connectivity after muscle fatigue. Brain Res. 1057, 10-16.
Perez, M. A., and Cohen, L. G. (2008). Mechanisms underlying functional changes in the primary motor cortex ipsilateral to an active hand. $J$. Neurosci. 28, 5631-5640.

Porter, R., and Lemon, R. (1993). Corticospinal Function and Voluntary Movement. Oxford: Clarendon Press.

Raz, N., Ghisletta, P., Rodrigue, K. M., Kennedy, K. M., and Lindenberger, U. (2010). Trajectories of brain aging in middle-aged and older adults: regional and individual differences. Neuroimage 51, 501-511.

Raz, N., Gunning-Dixon, F., Head, D., Williamson, A., and Acker, J. D. (2001). Age and sex differences in the cerebellum and the ventral pons: a prospective MR study of healthy adults. AJNR Am. J. Neuroradiol. 22, 1161-1167.

Raz, N., Rodrigue, K.M., and Haacke, E.M. (2007). Brain aging and its modifiers: insights from in vivo neuromorphometry and susceptibility weighted imaging. Ann. N. Y. Acad. Sci. 1097, 84-93.

Reuter-Lorenz, P. A., and Cappell, K. A. (2008). Neurocognitive aging and the compensation hypothesis. Curr. Dir. Psychol. Sci. 17, 177-182.

Reuter-Lorenz, P.A., and Lustig, C. (2005). Brain aging: reorganizing discoveries about the aging mind. Curr. Opin. Neurobiol. 15, 245-251.

Ridding, M. C., Brouwer, B., and Nordstrom, M. A. (2000). Reduced interhemispheric inhibition in musicians. Exp. Brain Res. 133, 249-253.

Rogers, B. P., Morgan, V. L., Newton, A. T., and Gore, J. C. (2007). Assessing functional connectivity in the human brain by fMRI. Magn. Reson. Imaging 25, 1347-1357.

Seidler, R. D., Alberts, J. L., and Stelmach, G. E. (2002). Changes in multi-joint performance with age. Motor Control 6, 19-31.

Seidler, R. D., Bernard, J. A., Burutolu, T. B., Fling, B. W., Gordon, M. T., Gwin, J. T., Kwak, Y., and Lipps, D. B. (2010). Motor control and aging: links to agerelated brain structural, functional, and biochemical effects. Neurosci. Biobehav. Rev. 34, 721-733.
Serrien, D. J., Ivry, R. B., and Swinnen, S. P. (2006). Dynamics of hemispheric specialization and integration in the context of motor control. Nat. Rev. Neurosci. 7, 160-166.

Serrien, D. J., Strens, L. H., Oliviero, A. and Brown, P. (2002). Repetitive transcranial magnetic stimulation of the supplementary motor area (SMA) degrades bimanual movement control in humans. Neurosci. Lett. 328, 89-92.

Shim, J. K., Kim, S. W., Oh, S. J., Kang, N., Zatsiorsky, V. M., and Latash, M. L. (2005). Plastic changes in interhemispheric inhibition with practice of a two-hand force production task: a transcranial magnetic stimulation study. Neurosci. Lett. 374, 104-108.

Stancak, A., Cohen, E. R., Seidler, R. D., Duong, T. Q., and Kim, S. G. (2003). The size of corpus callosum correlates with functional activation of medial motor cortical areas in bimanual and unimanual movements. Cereb. Cortex 13, 475-485.

Sullivan, E. V., Rohlfing, T., and Pfefferbaum, A. (2010). Quantitative fiber tracking of lateral and interhemispheric white matter systems in normal aging: relations to timed performance. Neurobiol. Aging 31, 464-481.

Talelli, P., Ewas, A., Waddingham, W., Rothwell, J. C., and Ward, N. S. (2008a). Neural correlates of agerelated changes in cortical neurophysiology. Neuroimage 40, 1772-1781.

Talelli, P., Waddingham, W., Ewas, A. Rothwell, J. C., and Ward, N. S. (2008b). The effect of age on taskrelated modulation of interhemispheric balance. Exp. Brain Res. 186, 59-66.

Uddin, L. Q., Mooshagian, E., Zaidel, E., Scheres, A., Margulies, D. S., Clare Kelly, A. M., Shehzad, Z., Adelstein, J. S., Castellanos, F. X., Biswal, B. B., and Milham, M. P. (2008). Residual functional connectivity in the split-brain revealed with resting-state functional MRI. Neuroreport 19, 703-709.

van den Berg, F. E., Swinnen, S. P., and Wenderoth, N. (2010). Hemispheric asymmetries of the premotor cortex are task specific as revealed by disruptive TMS during bimanual versus unimanual movements. Cereb. Cortex 20, 2842-2851.

Vercauteren, K., Pleysier, T., Van Belle, L., Swinnen, S. P., and Wenderoth, N. (2008). Unimanual muscle activation increases interhemispheric inhibition from the active to the resting hemisphere. Neurosci. Lett. 445, 209-213.

Vincent, J. L., Patel, G. H., Fox, M. D., Snyder, A. Z., Baker, J. T., Van Essen, D. C., Zempel, J. M., Snyder, L. H., Corbetta, M., and Raichle, M. E. (2007). Intrinsic functional architecture in the anaesthetized monkey brain. Nature 447, 83-86.

Wahl, M., Lauterbach-Soon, B., Hattingen, E., Jung, P., Singer, O., Volz, S., Klein, J. C., Steinmetz, H., and Ziemann, U. (2007). Human motor corpus callosum: topography, somatotopy, and link between microstructure and function. J. Neurosci. 27, 12132-12138. Ward, N. S., and Frackowiak, R. S. (2003). Age-related changes in the neural correlates of motor performance. Brain 126(Pt 4), 873-888.

Conflict of Interest Statement: The authors declare that the research was conducted in the absence of any commercial or financial relationships that could be construed as a potential conflict of interest.

Received: 05 February 2011; paper pending published: 07 March 2011; accepted: 10 March 2011; published online: 21 March 2011.

Citation: Fling BW, Peltier SJ, Bo J, Welsh $R C$ and Seidler RD (2011) Age differences in interhemispheric interactions: callosal structure, physiological function, and behavior. Front. Neurosci. 5:38. doi: 10.3389/fnins.2011.00038

Copyright (c) 2011 Fling, Peltier, Bo, Welsh and Seidler. This is an open-access article subject to an exclusive license agreement between the authors and Frontiers Media SA, which permits unrestricted use, distribution, and reproduction in any medium, provided the original authors and source are credited. 